\title{
The Disposition of Sulfoxone and Solasulfone in Leprosy Patients
}

\author{
J. H. PETERS \\ J. F. MURRAY, JR \\ and \\ G. R. GORDON \\ Stanford Research Institute, Menlo Park, California, USA \\ and \\ R. R. JACOBSON \\ United States Public Health Service Hospital, Carville, Louisiana, USA
}

\begin{abstract}
Sulfoxone was administered to 14 patients and the levels of dapsone (DDS) and monoacetyldapsone (MADDS) in plasma and urine were determined by spectrophotofluorometric techniques. Peak plasma levels of DDS were approximately 600 $\mathrm{ng} / \mathrm{ml} \mathrm{5-8} \mathrm{h}$ after treatment with $330 \mathrm{mg}$ sulfoxone. The urinary excretion pattern of DDS and MADDS after this drug was similar to that found after DDS treatment, but total DDS excretion was lower. The results indicate that regular sulfoxone therapy provides plasma levels of DDS that would be expected to be therapeutically effective and to protect patients from the development of DDS-resistant leprosy.

A recently developed high pressure liquid chromatographic fluorometric procedure was used to determine plasma levels of DDS, MADDS and parent drug in six patients receiving solasulfone. After a single $500-\mathrm{mg}$ intramuscular injection, plasma levels of DDS were only slightly above the minimal inhibitory concentration of DDS for Mycobacterium leprae, but the concentration increased 4-fold af ter six 500-mg twice-weekly doses. The rate of disappearance of solasulf one was rapid, but concurrent DDS and MADDS clearance times were longer than after DDS treatment. Direct relationships were found between 24-h DDS and solasulfone levels and among the disappearance rates of DDS, MADDS and solasulfone. Low levels of DDS after a single dose of solasulfone, as may be encountered in interrupted therapy, could be accompanied by an unusually high risk of the emergence or the selection of DDS-resistant Myco. leprae in certain patients.
\end{abstract}

\section{Introduction}

Earliest attempts to employ dapsone (DDS) therapeutically for treatment of leprosy patients were thwarted because it produced severe complications in the doses of 1 to $2 \mathrm{~g}$ thought necessary (Brownlee, 1950). To reduce the toxicity of DDS, several water-soluble derivatives (i.e., glucosulfone (glucosulfone sodium, Promin), sulfoxone (sulfoxone sodium, Diasone), and sol asulfone (Sulphetrone)) were synthesized and were used extensively in leprosy therapy (Faget et al., 1943; Lowe and Smith, 1949). Later studies (Smith, 1949a; Lowe, 1952) provided 
evidence that these compounds derived their activity from conversion to DDS. Concurrently, because therapeutic trials with lower doses of DDS in leprosy patients (Lowe, 1952) were successful with few complications, these watersoluble sulfones were discarded in favor of primary DDS therapy. Now, three decades later, several retrospective studies (Shepard et al., 1969; Jacobson and Trautman, 1971; Levy et al., 1972; Jacobson, 1973; Meade et al., 1973) have indicated that resistance to DDS was a serious attendant complication to the use of these water-soluble sulfones.

The disposition of these water-soluble sulfones in man was determined earlier by applying the Bratton-Marshall procedure for measuring aromatic amines (Lowe, 1952). However, this technique possesses limited sensitivity and selectivity, and in many casés DDS levels could not be detected after treatment (Smith, 1949b). The need for measurements of greater sensitivity was emphasized by the finding that the minimal inhibitory concentration (MIC) of DDS was in the range of 2 to $10 \mathrm{ng} / \mathrm{ml}$ of plasma in mice or rats infected with Mycobacterium leprae (Ozawa et al., 1971; Peters et al., 1972c). Subsequent analytic developments for measuring small amounts of DDS in plasma (Ellard and Gammon, 1969; Peters et al., 1970; Murray et al.., 1971; 1975) have made possible a realistic assessment of the DDS levels obtained in patients treated with these water-soluble sulfones. Now we can examine the suspected relationship between levels of DDS attained and the possible predisposition of patients receiving these drugs to DDS resistance.

In this study, we measured the levels of DDS and its major metabolite, monoacetyldapsone (MADDS), in the plasma of eight patients and in the urine of six patients receiving sulfoxone. Total DDS in the urine was also measured. In addition, we determined the disposition of DDS after three weeks of regular solasulfone therapy and contrasted these results with those obtained after a single treatment with solasulfone.

\section{Methods}

\section{PATIENTS AND TREATMENTS}

The participants in these studies were part of the patient population at the USPHS Hospital, Carville, La, U.S.A. They were fully informed of the purposes of the studies and participated voluntarily. The patients were divided into four groups. The composition of each was determined either by the drug received, the body fluid under study, or the treatment schedule. The patients ranged in age from 47 to 90 years and in body weight from 52 to $95 \mathrm{~kg}$.

Sulfoxone (Abbott Laboratories, Chicago, Illinois, U.S.A.) was given as a single oral dose of $330 \mathrm{mg}$. Heparinized blood samples $(10 \mathrm{ml})$ were taken at the times indicated in Table 1 from the first group receiving this drug. Plasma was immediately prepared and stored frozen. Urine was collected from the second group during $24 \mathrm{~h}$ following the same dose of sulfoxone (Table 1). The volumes of urine were measured and 50-ml aliquots were stored frozen.

The third group of patients received twice-weekly intramuscular injections of $500 \mathrm{mg}$ of solasulfone (Burroughs, Wellcome and Co., Ltd., Bombay, India) for three weeks. Plasma samples were obtained after the sixth dose at the times shown in Table 2. To compare the results in patients on a regular schedule with those obtained from a single administration (as might be encountered in 
interrupted therapy), we repeated the study in a fourth group whose members received only one injection of solasulfone (Table 3). All samples of plasma and urine were shipped via air on dry ice to the SRI laboratories for subsequent analysis.

In the past, chemotherapeutic treatment schedules of the two sulfone derivatives were: $330 \mathrm{mg}$ oral sulfoxone, daily; or $500 \mathrm{mg}$ intramuscular solasulfone twice weekly.

\section{ASSAY PROCEDURES}

Determinations of the possible influence of sulfoxone in the direct fluorometric procedure for measuring DDS and MADDS in plasma (Peters et al., 1970) showed that $0.50 \mu \mathrm{g}$ of sulfoxone (equivalent to $0.26 \mu \mathrm{g}$ DDS, if hydrolyzed) contributed $<0.01 \mu \mathrm{g}$ DDS. Because sulfoxone did not interfere in the assays for DDS and MADDS, this procedure was used to determine DDS and MADDS in plasma and in urine of patients receiving sulfoxone. Total DDS was also determined in urine after hydrolysis in $2 \mathrm{~N} \mathrm{HCl}\left(100^{\circ} \mathrm{C}\right)$. Sulfoxone was hydrolyzed quantitatively to DDS by these conditions; therefore, the total DDS measured in urine would include the DDS conjugates known to be hydrolyzed to DDS (Peters $e t$ al., 1970) and any unchanged sulfoxone.

Procedures previously employed to determine DDS and MADDS (Peters et al., 1970; Murray et al., 1971) were not applicable to assays of plasma from patients receiving solasulfone because this compound was rapidly hydrolyzed to DDS under the alkaline extraction conditions used in those methods. To avoid hydrolysis of solasulfone, we extracted plasma that was buffered to $\mathrm{pH} 7.4$ as described below. Preliminary studies indicated that solasulfone in this buffer $(0.6$ to $1.0 \mathrm{mg} / \mathrm{ml})$ was hydrolyzed to the extent of $<0.2 \% /$ day $\left(21^{\circ} \mathrm{C}\right)$ under these extraction conditions. Results of measurements of DDS and MADDS were the same (within 5\%) in extracts of alkalinized or buffered plasma that did not contain solasulfone. Also, in some patients the levels of DDS and MADDS were found to be below the limits of sensitivity of our previously published procedures. Therefore, we employed recent modifications of a chromatographic-fluorometric technique for measuring DDS and MADDS (Murray et al., 1975) that increased the sensitivity to $0.1 \mathrm{ng}$ DDS or MADDS/ml of plasma.

To determine DDS and MADDS in plasma from patients receiving solasulfone, we added aliquots of plasma $(0.50 \mathrm{ml})$ to $1.8-\mathrm{ml}$ vials that contained $0.50 \mathrm{ml}$ of $0.05 \mathrm{M} \mathrm{KH}_{2} \mathrm{PO}_{4} \mathrm{Na}_{2} \mathrm{HPO}_{4}, \mathrm{pH} 7.4$. Ethyl acetate $(0.70 \mathrm{ml})$ was added and the vial was closed with a cap lined with a small piece of aluminium foil $(1 \times 1 \mathrm{~cm})$. Extraction was carried out on an Eberbach shaker (Ann Arbor, Michigan, U.S.A.) for $10 \mathrm{~min}$ at $100 \mathrm{strokes} / \mathrm{min}$. This slow shaking rate retarded formation of an emulsion. After centrifugation to separate the phases, DDS and MADDS in the ethyl acetate phase were determined fluorometrically af ter high pressure liquid chromatographic separation on a column of silica gel. DDS and MADDS calibration standards, solasulf one solutions, and reagent blanks were subjected to the same procedure. These assays revealed that the DDS content of the solasulfone preparation was $0.31 \%$.

Because the recovery of solasulfone (as DDS) after mild alkaline hydrolysis of standard solutions was found to be nearly quantitative $(94.1 \pm 2.00 \%$, mean \pm S.E. $)$, we employed this method to measure solasulfone in plasma. An aliquot of plasma $(0.01$ to $0.50 \mathrm{ml})$ was hydrolyzed in a solution that contained $0.50 \mathrm{ml}$ of $1 \mathrm{~N}$ 
$\mathrm{NaOH}, 0.02 \mathrm{ml}$ of thiodiglycol (to prevent the degradation of DDS), and sufficient $\mathrm{H}_{2} \mathrm{O}$ to adjust the final volume to $1.0 \mathrm{ml}$. The mixture was allowed to stand for $2 \mathrm{~h}$ at room temperature $\left(21^{\circ} \mathrm{C}\right)$. Then the DDS formed was extracted into $0.70 \mathrm{ml}$ of ethyl acetate and the extract was chromatographed as described. The recovery of solasulfone (as DDS) from standards in plasma was $82.0 \pm 3.57 \%$ (mean \pm S.E.). We have reported values obtained by this technique as "alkali-labile DDS" rather than as solasulfone because the procedure is indirect. For this reason, we have not corrected the experimental values for the lower than theoretical recovery from standards.

Previous investigators (Alexander et al., 1970; Peters et al., 1972a; Ellard et al., 1974) concluded that after DDS treatment, plasma contained only DDS and MADDS and no other conjugates of DDS easily hydrolyzed to the parent drug. On the basis of these observations and the established susceptibility of solasulfone to mild alkaline hydrolysis, we have interpreted the very large increases of DDS found af ter this treatment of plasma from patients receiving solasulfone to be the administered drug.

The half-times of disappearance $\left(T^{1 / 2}\right)$ of the various compounds were calculated from the regression lines representing the logarithmic decay of their concentrations with time. Only those regression lines yielding correlation coefficients $<-0.9000$ were considered to yield valid $T^{1 / 2}$ values. Differences between $T \frac{1}{2}$ values were determined by comparing the slopes of the regression lines.

\section{Results and Discussion}

\section{SULFOXONE STUDIES}

The upper part of Table 1 presents the mean levels of DDS and MADDS found in the patients at $4,5.5$, and $8 \mathrm{~h}$ following an oral dose of $330 \mathrm{mg}$ sulfoxone. These values suggest relatively slow hydrolysis of sulfoxone, with peak levels of DDS and MADDS occurring between 5.5 and $8 \mathrm{~h}$. These mean levels of DDS at the later times after sulfoxone are similar to the mean levels of DDS ranging from 560 to $680 \mathrm{ng} / \mathrm{ml}$ at 6 and $8 \mathrm{~h}$ that we found in Filipino and Indian subjects receiving $50 \mathrm{mg}$ DDS orally (Peters et al., 1974a; 1975). Because $330 \mathrm{mg}$ sulfoxone contains $169 \mathrm{mg}$ DDS (assuming complete hydrolysis to DDS), we can estimate that an approximately three-fold higher molar dose of sulfoxone than of DDS was required to yield similar plasma levels of DDS. Similar quantitative relationships were found in the blood levels of DDS in mice (Titus and Bernstein, 1949) and rabbits (Francis and Spinks, 1950) after administration of DDS and sulfoxone. These authors also reported that sulfoxone exhibited one-half to one-tenth the antibacterial activity of DDS when the two drugs were compared in equimolar doses. Regardless of the comparisons made above, it is clear that $330 \mathrm{mg}$ sulfoxone given orally yields peak plasma levels of DDS that are substantially higher than the MIC of DDS for Myco. leprae (Ozawa et al., 1971; Peters et al., 1972c).

Our findings on the 24h urinary excretion of DDS, MADDS and total DDS by six patients receiving $330 \mathrm{mg}$ sulfoxone are summarized in the lower part of Table 1. Comparison of these mean values with corresponding percentages of a $100-\mathrm{mg}$ dose of DDS (5.4\% as DDS, $0.55 \%$ as MADDS and $31.1 \%$ as total DDS) excreted in $24 \mathrm{~h}$ by subjects studied earlier (Gelber et al., 1971) indicates that the current patients excreted fractions of the dose as DDS and MADDS that were not 
TABLE I

Plasma levels and urinary excretion of DDS, MADDS and total DDS in patients receiving $330 \mathrm{mg}$ sulfoxone orally

\begin{tabular}{cccc}
\hline $\begin{array}{c}\text { Hours after } \\
\text { treatment } a\end{array}$ & DDS & MADDS & Total DDS \\
\hline \multicolumn{5}{c}{ Plasma level $(\mathrm{ng} / \mathrm{ml})$} \\
$4(4)$ & $305 \pm 110.6$ & $140 \pm 59.0$ & $-b$ \\
$5.5(5)$ & $636 \pm 175.8$ & $218 \pm 68.2$ & $-b$ \\
$8(5)$ & $656 \pm 172.7$ & $184 \pm 50.4$ & $-b$ \\
& \multicolumn{5}{c}{ Urinary excretion (\% of dose) } \\
$0-24(6)$ & $4.3 \pm 1.34$ & $0.34 \pm 0.121$ & $21 \pm 4.9$ \\
\hline
\end{tabular}

$a$ Values in parentheses are the number of patients studied. Other values in the table are the means \pm standard errors of the mean.

$b$ Not measured.

significantly different from those receiving DDS. However, less total DDS $(P<0.05)$ was excreted after sulfoxone than after DDS. The finding of less total DDS, even though the assay procedure measures unchanged sulfoxone as well as DDS conjugates, suggests that sulfoxone contributed very little, if at all, to the total DDS measured. Smith (1949a) also reported a large difference in the urinary excretion of total DDS during three days following oral sulfoxone and DDS by patients ( $53 \%$ versus $80 \%$ ), and concluded that this was due primarily to relatively poor absorption of sulfoxone from the gastrointestinal tract.

Based on the plasma levels and urinary excretion of DDS after $330 \mathrm{mg}$ sulfoxone treatment, it would seem that this dose is roughly equivalent to giving $50 \mathrm{mg}$ DDS. One could anticipate, therefore, that such a dose of sulfoxone, taken regularly, would be adequate for therapy and would not be accompanied by unusual risk of the emergence or selection of DDS-resistant Myco. leprae.

\section{SOLASULFONE STUDIES}

As described in the Methods section, we found that the solasulfone preparation contained $0.31 \%$ DDS. Thus, the $500 \mathrm{mg}$ of solasulf one administered contained $1.55 \mathrm{mg}$ of DDS, and we would expect to find levels of DDS in the plasma at least reflective of that dose of DDS. The only pertinent data available on this point are from Ellard et al. (1971), who estimated a mean serum level of $18 \mathrm{ng} \mathrm{DDS} / \mathrm{ml}$ in patients at $3 \mathrm{~h}$ af ter oral administration of $1 \mathrm{mg}$ DDS.

Table 2 shows that $1 \mathrm{~h}$ after injection of solasulfone, DDS levels in three patients on scheduled therapy ranged from 46.6 to $142 \mathrm{ng} / \mathrm{ml}$ (mean, 80.7); the concurrent mean level of MADDS was $21.0 \mathrm{ng} / \mathrm{ml}$ (range, 3.5 to 40.5 ). Substantially higher levels of alkali-labile DDS (solasulfone) were found at this time. They ranged from 5910 to $11,000 \mathrm{ng} / \mathrm{ml}$ and averaged $8140 \mathrm{ng} / \mathrm{ml}$. The mean DDS and MADDS levels increased moderately by the next blood sampling at $24 \mathrm{~h}(98.4$ and $32.9 \mathrm{ng} / \mathrm{ml}$, respectively) and thereaf ter declined slowly to the 72-h level. In contrast, the solasulfone levels decreased dramatically after $1 \mathrm{~h}$. In these patients, the 24-h DDS and alkali-labile DDS levels were directly related 
TABLE 2

Plasma levels and T1/2 values of DDS, MADDS and alkali-labile DDS in patients receiving multiple doses of $500 \mathrm{mg}$ solasulfone intramuscularly

\begin{tabular}{|c|c|c|c|c|}
\hline \multirow{2}{*}{$\begin{array}{l}\text { Patient } \\
\text { No. }\end{array}$} & \multirow{2}{*}{$\begin{array}{c}\text { Hours after } \\
\text { treatment }\end{array}$} & \multicolumn{3}{|c|}{ Plasma level $(\mathrm{ng} / \mathrm{ml})$} \\
\hline & & DDS & MADDS & $\begin{array}{l}\text { Alkali-labile } \\
\operatorname{DDS}^{a}\end{array}$ \\
\hline \multirow[t]{5}{*}{ I } & 1 & 46.6 & 3.5 & 11,000 \\
\hline & 24 & 60.7 & 10.6 & 2980 \\
\hline & 48 & 56.8 & 9.3 & 814 \\
\hline & 72 & 44.4 & 6.8 & 242 \\
\hline & $T^{1 / 2}(\mathrm{~h})^{b}$ & 106 & 75 & 13 \\
\hline \multirow[t]{6}{*}{ II } & 24 & 177 & 28.7 & 4350 \\
\hline & 48 & 167 & 26.4 & 1960 \\
\hline & 72 & 143 & 21.4 & 940 \\
\hline & $1 c$ & 142 & 19.1 & 7500 \\
\hline & 72 & 110 & 16.7 & 1060 \\
\hline & $T^{1 / 2}(\mathrm{~h}) b$ & 156 & 113 & 22 \\
\hline \multirow[t]{5}{*}{ III } & 1 & 53.4 & 40.5 & 5910 \\
\hline & 24 & 57.6 & 59.5 & 2860 \\
\hline & 48 & 52.2 & 56.0 & 1050 \\
\hline & 72 & 46.0 & 44.0 & 420 \\
\hline & $T^{d} / 2(\mathrm{~h}) b$ & 148 & 110 & 17 \\
\hline
\end{tabular}

$a$ These values were obtained after hydrolysis as described in the text.

$b$ Values were calculated from the slopes of the regression lines obtained from plasma data at 24,48 and $72 \mathrm{~h}(\mathrm{r}<-0.9)$.

$c$ This sample was collected $97 \mathrm{~h}$ af ter the previous dose.

$(P<0.05)$, but no correlation was found between either of these two and the MADDS levels.

Also presented in Table 2 are the calculated $T^{1} / 2$ values for the three measured compounds in each patient. Solasulfone was cleared rapidly and the $T 1 / 2$ values ranged from 13 to $22 \mathrm{~h}$. On the other hand, both DDS and MADDS levels declined very slowly, yielding $T^{1 / 2}$ values ranging from 75 to $156 \mathrm{~h}$ in the three patients. An apparent dependence of the $T^{1 / 2}$ values for DDS and MADDS on the $T^{T / 2}$ of solasulfone was suggested by the finding that Patient II exhibited the longest $T^{1 / 2}$ values for all three compounds with Patients III and I showing slightly lower $T^{1 / 2}$ values in the same sequence.

The $T \frac{1}{2}$ values for DDS and MADDS in patients on multiple-dose therapy were substantially higher than the mean $T^{1 / 2}$ values for these compounds of 28 to $31 \mathrm{~h}$ that we observed previously in African, Filipino or South Indian subjects or patients receiving DDS orally (Peters et al., 1972a;1972b;1975). The longer $T^{1 / 2}$ values of DDS and MADDS after solasulfone may have resulted from slow hydrolysis of solasulfone so that the circulation was continuously supplied with DDS. However, the rapid disappearance of solasulfone suggests that other factors must have contributed. One of these could be a relatively slow release of DDS formed from solasulfone at the site of administration. Thus, the multiple 
administration of solasulfone may result in a partial repository effect. In this regard, we found previously (Peters et al., 1974b) that DDS and MADDS are cleared very slowly from the circulation with $T^{1 / 2}$ values of 42 days following the intramuscular administration of $225 \mathrm{mg}$ of acedapsone, the repository form of DDS. Also, other tissues may release DDS slowly following their saturation with DDS after the five or six doses of solasulfone. Recent studies in mice and rats fed diets containing DDS indicate that certain tissues exhibit levels of DDS and MADDS that are several times greater than plasma levels determined concurrently (Gordon et al., 1974; Murray et al., 1974). Whether these latter observations are applicable to patients receiving low doses of DDS regularly has yet to be determined.

The 24-h levels of DDS ranging from 57.6 to $177 \mathrm{ng} / \mathrm{ml}$ in the three patients receiving solasulfone are roughly comparable to the mean value of $800 \mathrm{ng} \mathrm{DDS} / \mathrm{ml}$ at $24 \mathrm{~h}$ (Lowe, 1952) in patients receiving $3 \mathrm{~g}$ of solasulfone twice weekly by intramuscular injection, considering the six-fold difference in the doses. More recently, Gelber et al. (1974) reported DDS levels ranging from 60 to $120 \mathrm{ng} / \mathrm{ml}$ at $24 \mathrm{~h}$ after a single intramuscular injection of $1.5 \mathrm{~g}$ of solasulfone. These levels are similar to concentrations we found at $24 \mathrm{~h}$ after giving one-third of this dose twice weekly, emphasizing an apparent accumulation of DDS and MADDS with the multiple treatments.

TABLE 3

Plasma levels and $T \frac{1}{2}$ values of DDS, MADDS and alkali-labile DDS in patients receiving a single dose of $500 \mathrm{mg}$ solasulfone intramuscularly

\begin{tabular}{|c|c|c|c|c|}
\hline \multirow[b]{2}{*}{$\begin{array}{l}\text { Patient } \\
\text { No. }\end{array}$} & \multirow[b]{2}{*}{$\begin{array}{l}\text { Hours after } \\
\text { treatment }\end{array}$} & \multicolumn{3}{|c|}{ Plasma level $(\mathrm{ng} / \mathrm{ml})$} \\
\hline & & DDS & MADDS & $\begin{array}{l}\text { Alkali-labile } \\
\operatorname{DDS}^{a}\end{array}$ \\
\hline \multirow[t]{2}{*}{ IV } & $\begin{array}{r}0 \\
24 \\
48 \\
72\end{array}$ & $\begin{array}{l}<0.2 \\
17.2 \\
18.6 \\
17.7\end{array}$ & $\begin{array}{l}<0.3 \\
14.7 \\
16.5 \\
13.0\end{array}$ & $\begin{array}{c}<0.2 \\
2250 \\
817 \\
314\end{array}$ \\
\hline & $T^{1 / 2}(\mathrm{~h}) b$ & $-c$ & $-c$ & 17 \\
\hline \multirow[t]{2}{*}{ V } & $\begin{array}{r}0 \\
24 \\
48 \\
72\end{array}$ & $\begin{array}{r}<0.2 \\
16.5 \\
6.9 \\
3.4\end{array}$ & $\begin{array}{r}<0.3 \\
5.5 \\
1.8 \\
0.7\end{array}$ & $\begin{array}{c}<0.2 \\
1600 \\
394 \\
95.6\end{array}$ \\
\hline & $T^{1 / 2(\mathrm{~h}) b}$ & 21 & 16 & 12 \\
\hline \multirow[t]{2}{*}{ VI } & $\begin{array}{r}0 \\
24 \\
48 \\
72\end{array}$ & $\begin{array}{l}<0.2 \\
26.1 \\
31.0 \\
31.1\end{array}$ & $\begin{array}{l}<0.3 \\
12.8 \\
14.7 \\
16.0\end{array}$ & $\begin{array}{c}<0.2 \\
2940 \\
716 \\
211\end{array}$ \\
\hline & $T^{1 / 2(\mathrm{~h}) b}$ & $-c$ & $-c$ & 13 \\
\hline
\end{tabular}

$a$ These values were obtained after hydrolysis as described in the text.

$b$ Values were calculated from the slopes of the regression lines obtained from plasma data at 24,48 and $72 \mathrm{~h}(r \leqslant-0.9)$.

c $T^{1 / 2}$ was considered invalid because the $r$ value was $>-0.9$. 
From the levels of DDS found in these patients receiving regular twice-weekly injections of solasulfone, we would not anticipate an unusual risk of the emergence or selection of DDS-resistant Myco. leprae.

However, departure from this regular schedule may yield levels of DDS below the MIC for Myco. leprae resulting in poor therapeutic response. To test this possibilitv, we determined the levels of the three compounds in patients receiving only a single $500-\mathrm{mg}$ dose of solasulfonc. The levels of DDS, MADDS and solasulfone found are listed in Table 3. Mean DDS levels at 24, 48 and $72 \mathrm{~h}$ of $19.9,18.8$ and $17.4 \mathrm{ng} / \mathrm{ml}$. respectively, were significantly lower $(P<0.05)^{*}$ than the corresponding means in the group who received multiple doses over a three-week period. In Patients IV and VI, DDS did not decline after $24 \mathrm{~h}$ and, therefore, no valid $T^{1} / 2$ values could be calculated. However, in Patient $V$, the levels of all three compounds declined exponentially and $T 1 / 2$ values of DDS and MADDS were found to be 21 and $16 \mathrm{~h}$, respectively. This patient exhibited DDS levels at 48 and $72 \mathrm{~h}$ in the range of the MIC for DDS against Myco. leprae, and would be expected to exhibit a high potential for the emergence or selection of DDS-resistant $M y c o$. leprae if not treated regularly.

Solasulfone levels in these patients were not markedly different from those receiving multiple doses. $T^{1 / 2}$ values shown in the last column of this table were similar to those found in the previous group.

The lack of exponential decay of DDS plasma levels following a single dose of solasulfone was also apparent in the findings of Gelber et al. (1974). Using the plasma DDS levels reported by this group, we could not calculate valid $(r<-0.9)$ $T \frac{1}{2}$ values for one-half of the eight patients they studied.

These investigations have shown that DDS levels adequate for chemotherapeutic activity are obtained during solasulfone treatment with $500 \mathrm{mg}$ twice weekly. However, interrupted treatment, as exemplified by the studies after a single dose, could yield dangerously low levels of DDS in certain patients with the probable attendant potentiality of the emergence or selection of DDS-resistant Myco. leprae.

\section{Acknowledgement}

This research was supported in part by the United States-Japan Cooperative Medical Science Program administered by the National Institute of Allergy and Infectious Diseases (Grant AI 08214 and Contract NIH-70-2283), National Institutes of Health, Department of Health, Education and Welfare.

\section{References}

Alexander, J. O'D., Young, E., McFadyen, 1., Fraser, N. G.. Duguid. W. P. and Meredith. F. M. (1970). Absorption and excretion of ${ }^{35} \mathrm{~S}$ dapsone in dermatitis herpetiformis. Br. $J$. Derm. 83, 620.

Brownlee, G. (1950). Correspondence: Early experiences with DDS in man. Int. J. Lepr. 18, 247.

Ellard, G. A. and Gammon, P. T. (1969). A fluorometric method for the simultaneous determination of 4,4'-diaminodiphenyl sulfone (DDS), $N$-acetyl-DDS (MADDS) and $N, N^{\prime}$-diacetyl-DDS (DADDS) in serum or urine. Int. J. Lepr. 37, 398.

Ellard, G. A., Gammon, P. T., Rees, R. J. W. and Waters, M. F. R. (1971). Studies on the determination of the minimal inhibitory concentration of $4,4^{\prime}$-dia mino-diphenyl-sulphone (dapsone, DDS) against Mycobacterium leprae. Lepr. Rev. 42, 101.

*Employing the Mann-Whitney test (Siegel, 1956). 
Ellard, G. A., Gammon, P. T., Savin, J. A. and Tan, R. S.-H. (1974). Dapsone acetylation in dermatitis herpetiformis. Br. J. Derm. 90, 441 .

Faget, G. H., Pogge, R. C., Johansen, F. A., Dinan, J. F., Prejean, B. M. and Eccles, C. (i. (1943). The Promin treatment of leprosy. A progress report. Publ. Hlth Rep., Wash. 58, 1729.

Francis, J. and Spinks, A. (1950). Antibacterial action and metabolism of five sulfones. Br. J. Pharmac. Chemother. 5, 565.

Gelber, R., Peters, J. H., Gordon, G. R., Glazko, A. J. and Levy, L. (1971). The polymorphic acetylation of dapsone in man. Clin. Pharmac. Therap. 12, 225.

Gelber, R. H., Gooi, J. H. C., Waters, M. F. R. and Rees, R. J. W. (1974). The pharmacology of sulphetrone and its implications in sulphone resistance. Lepr. Rev. 45, 308.

Gordon, G. R., Ghoul, D. C., Murray, J. F., Jr, Peters, J. H. and Levy, L. (1974). Tissue levels of dapsone and monoacetyldapsone in rats and mice receiving dietary dapsone. Int. $J$. Lepr. 42, 373.

Jacobson, R. R. (1973). Sulphone-resistant leprosy: etiology, incidence and treatment in the United States. Tenth International Leprosy Congress, Bergen, Norway. Abstr., 202.

Jacobson, R. R. and Trautman, J. R. (1971). The treatment of leprosy with the sulfones. Int. J. Lepr. 39, 726.

Levy, L., Shepard, C. C. and Fasal, P. (1972). Clofazimine therapy of lepromatous leprosy caused by dapsone-resistant Mycobacterium leprae. Am.J. trop. Med. Hyg. $21,315$.

Lowe, J. (1952). Studies in sulphone therapy. Lepr. Rev. 23, 4.

Lowe, J. and Smith, M. (1949). The chemotherapy of leprosy in Nigeria. Int. J. Lepr. 17, 181.

Meade, T. W., Pearson, J. M. H., Rees, R. J. W. and North, W. R. S. (1973). The epidemiology of sulphone-resistant leprosy. Tenth International Leprosy Congress, Bergen, Norway. Abstr., 202.

Murray, J. F., Jr, Gordon, G. R., Gulledge, C. C. and Peters, J. H. (1975). Chromatographicfluorometric analysis of antileprotic sulfones. J. Chromat. 107, 67.

Murray, J. F., Jr, Gordon, G. R. and Peters, J. H. (1971). A chromatographic-fluorometric procedure for the determination of nanogram quantities of antileprotic sulfones. J. Lab. clin. Med. 78, 464.

Murray, J. F., Jr, Gordon, G. R. and Peters, J. H. (1974). Tissue levels of dapsone and monoacetyldapsone in Lewis rats receiving dietary dapsone. Proc. West. Pharmacol. Soc. 17,150 .

Ozawa, T., Shepard, C. C. and Karat, A. B. A. (1971). Application of spectrophotofluorometric procedures to some problems in Mycobacterium leprae infections in mice and man treated with dapsone (DDS), diacetyl-DDS (DADDS), and di-formyl-DDS (DFD). A m. J. trop. Med. Hyg. 20, 274.

Peters, J. H., Gordon, G. R. and Colwell, W. T., Jr (1970). The fluorometric measurement of $4,4^{\prime}$-diaminodiphenyl sulfone and its acetylated derivatives in plasma and urine. J. Lab. clin. Med. 76, 338.

Peters, J. H., Gordon, G. R., Ghoul, D. C., Tolentino, J. G., Walsh, G. P. and Levy, L. (1972a). The disposition of the antileprotic drug dapsone (DDS) in Philippine subjects. $A \mathrm{~m}$. J. trop. Med. Hyg. 21, 450.

Peters, J. H., Gordon, G. R., Karat, A. B. A. and Meyers, W. M. (1972b). Metabolic disposition of dapsone in Indian and African subjects. Int. J. Lepr. 40, 221.

Peters, J. H., Gordon, G. R., Murray, J. F., Jr, Fieldsteel, A. H. and Levy, L. (1972c). Minimal inhibitory concentration of dapsone for M. leprae in rats. Int. J. Lepr. 40, 467.

Peters, J. H., Gordon, G. R. and Karat, A. B. A. (1975). Polymorphic acetylation of the antibacterials, sulfamethazine and dapsone, in South Indian subjects. Am. J. trop. Med. Hyg. (In press.)

Peters, J. H., Gordon, G. R., Levy, L., Storkan, M. A., Jacobson, R. R., Enna, C. D. and Kirchheimer, W. F. (1974a). Metabolic disposition of dapsone in patients with dapsone-resistant leprosy. Am.J.trop. Med. Hyg. 24, 222.

Peters, J. H., Gordon, G. R., Murray, J. F., Jr and Levy, L. (1974b). Metabolic disposition versus therapeutic response to acedapsone. Int. J. Lepr. 42, 375.

Shepard, C. C., Levy, L. and Fasal, P. (1969). The sensitivity to dapsone (DDS) of Mycobacterium leprae from patients with and without previous treatment. Am. J. trop. Med. Hyg. 18, 258.

Siegel, S. (1956). Nonparametric Statistics for the Behavioral Sciences. p. 116. New York: McGraw-Hill Book Co. Inc. 
Smith, M. (1949a). A pharmacological study of three sulphones. Part I. Absorption, distribution and excretion. Lepr. Rev. 20, 78.

Smith, M. (1949b). A pharmacological study of three sulphones. Part II. Hydrolysis and specific toxic phenomena. Lepr. Rev. 20,128.

Titus, E. and Bernstein, J. (1949). The pharmacology of sulfones. Ann. N.Y. A cud. Sci. 52, 719. 